\begin{tabular}{|c|l|}
\hline Title & Relationship between thal lus size and apothecium density in two al pine umbilicate lichens \\
\hline Author(s) & Shimizu, A kira; Kubo, Takuya \\
\hline Citation & $\begin{array}{l}\text { The Lichenologist, 41/03), 285-297 } \\
\text { https://doi.org/L01017/S0024282909007762 }\end{array}$ \\
\hline Issue Date & 2009-05 \\
\hline Doc URL & http://hdl.handle.net/2115/38821 \\
\hline Rights & Copyright $\odot$ 2009 British Lichen Society \\
\hline Type & article (author version) \\
\hline File Information & 41-p285-297.pdf \\
\hline
\end{tabular}

Instructions for use 


\section{Relationship between thallus size and apothecium density in two alpine umbilicate lichens}

Akira SHIMIZU and Takuya KUBO

Running title: Thallus size and apothecium density

A. Shimizu and T. Kubo: Graduate School of Environmental Earth Science, Hokkaido University, Sapporo 060-0810, Japan

The total number of pages including the cover sheet: 29

Numbers of figures: 7

Numbers of tables: 2 
Abstract: The relationship between thallus size and apothecium density was studied in two umbilicate lichens, Umbilicaria cylindrica and Lasallia pensylvanica, growing in alpine rock surface environments. Samples of the two lichens were collected from the Daisetsuzan National Park, northern Japan. $U$. cylindrica produced many smaller apothecia, whereas L. pensylvanica had larger but fewer apothecia. To explain the differences in reproductive efforts between these two species, we analyzed the lichen data using a hierarchical Bayesian model in which the density of apothecia for each species was predicted by the thallus area and the sky openness index (SOI). The Bayesian model including unobservable effects, i.e., the random effects of lichen individuals and rock faces predicted that the apothecia densities for both species increased as the thallus area increased. The estimated coefficient of thallus area to apothecium density for U. cylindrica was larger than that for L. pensylvanica. We also detected a probably positive relationship between SOI and apothecium density for $U$. cylindrica, whereas none was detected for L. pensylvanica.

Key words: apothecia, aspect, Bayesian modeling, sky openness, thallus area. 


\section{Introduction}

Reproductive ecology of lichens is an emerging research field (Ramstad \& Hestmark 2001; Pringle et al. 2003; Jackson et al. 2006). The relationship between thallus size and the density of apothecia, i.e., the number of apothecia per unit area, has been a recent research focus in lichen reproductive ecology. Ramstad and Hestmark (2001) proposed that the total apothecium number was proportional to the thallus area in a coastal saxicolous lichen species, Umbilicaria spodochroa. This suggests the relationship is isometric, i.e., the density of apothecia is constant or does not depend on thallus size or thallus area. Pringle et al. (2003), however, stated that the apothecium density depended on thallus size in a foliose saxicolous species, Xanthoparmelia cumberlandia. These authors selected a statistical model, using the likelihood ratio test, in which they evaluated the log likelihood of two different models representing the relationship between apothecium density and thallus size. They showed that the model including the power of thallus size was the better predictor of apothecium number than the proportional relationship model.

The effects of the environmental factors on apothecium density have been discussed in several recent studies. Jackson et al. (2006) proposed a new model in which the relationship between thallus size and apothecium density was affected by the altitude of the sampling sites. They applied an allometric model assuming that the log of apothecium number could be predicted by a linear expression of the log of thallus area, and concluded that the allometric relationship varied with the 
altitude of the sampling site.

These examples of reports include not only the issue of biology but also that of statistics. We aim to address two problems in the modeling of apothecium density, including the correctness of terms that depend on both thallus size and environmental factors. The former factor concerns the functional form of the relationship between thallus size and apothecium number. In theory, a general but reasonable formula for the relationship is the allometric function as described in Jackson et al. (2006). This is because the number of apothecia is zero when the thallus size is zero. The proper probabilistic distribution for the apothecium number will not be a normal distribution but a Poisson distribution as in Pringle et al. (2003), because the data is countable. The latter problem, modeling of environmental factors, requires a carefully designed statistical model involving both fixed and random effects (e.g., Crawley 2005), i.e., factors of interest and nuisance ones. We focus on the light environment in lichen habitats as a fixed effect because recent studies have shown quantitative effects of light on lichen growth. Dahlman and Palmqvist (2003) demonstrated the importance of irradiance on thalli during the hydration period on the growth in two lichens, Nephroma arcticum and Peltigera aphthosa. Many studies have reported that thallus size and anatomy affects the water-holding capacity and thereby the photosynthetic rate (Larson 1984; Sancho \& Kappen 1989; Valladares et al. 1993; Gauslaa \& Solhaug 1998). Some studies of the light harvesting potential of lichens growing on rock surfaces have demonstrated the importance of the rock 
surface aspect on sunlight availability and the retention of water. Saxicolous lichen species show aspect-specific distributions, growth patterns and size-class frequencies (e.g., Armstrong 1975, 2002). For example, Monte (1993) reported the faster growth of lichens with Trentepohlia algae in northern aspects characterized by low light intensity and high humidity.

One of our objectives was to investigate the differences in the apothecium densities between two sympatric lichens inhabiting rock surfaces. The number of the environmental factors to be considered was controlled by choosing a suitable research site and by introducing modern statistical methodology. We collected apothecia data for two Umbilicariaceae species, Umbilicaria cylindrica and Lasallia pensylvanica along alpine trails at altitudes higher than $1560 \mathrm{~m}$ in northern Japan. Since the lichens at the research site are frequently hydrated by mists or the condensation even during daytime in summer, we consider the confounding effects of light and hydration to be of low importance. By introducing a Bayesian approach (e.g., Clark et al. 2003), we intended to separate the interesting factors from the nuisance ones such as unobservable characteristics of sampled rock faces. We developed a new Bayesian model to predict the number of apothecia per thallus area, and an index of sky openness on the rock face where lichens were sampled. 


\section{Materials and Methods}

\section{Study area}

Field surveys were conducted during the summers of 2004 and 2006 in the Daisetsuzan National Park, Hokkaido, Japan (about N $43^{\circ}$ and E $143^{\circ}$, Fig. 1). Elevations of the study sites ranged from 1560 to $2170 \mathrm{~m}$, areas above the timberlines (1200-1400 m). The sites comprised mostly volcanic boulders and alpine vegetation with patches of Pinus pumila scrub. The ground is under snow from the end of October until early May. The area belongs to a volcanic chain with components of different geological ages. Some areas around the active volcano, i.e. Mount Asahi and Mount Tokachi, have highly acidic environments (Katsui et al. 1953).

\section{Materials}

Boulders in the area are mainly covered with arctic-alpine or circumboreal lichen species. Among saxicolous species, umbilicate lichens are regarded as suitable materials for sampling and measuring whole individual thalli. Umbilicaria caroliniana Tuck., U. cylindrica (L.) Delise ex Duby and Lasallia pensylvanica (Hoffm.) Llano are common, U. torrefacta (Lightf.) Schrad. occurs more in the acidic areas, and U. exasperata Hoffm. and U. deusta (L.) Baumg. are found occasionally in the study area (Shimizu et al. 2004). Since $U$. caroliniana rarely produces apothecia, whereas $U$. cylindrica and L. pensylvanica bear many apothecia but no soredia or isidia, the two latter species were chosen for the study. 
In phytogeographic terms, $U$. cylindrica belongs to the Alpine Element and $L$. pensylvanica belongs to the Eastern Asiatic-Eastern North American Disjunctive Group (Kurokawa 2006). Morphologically, U. cylindrica has variable, polyphyllous and curved thalli, whereas L. pensylvanica has monophyllous and plain thalli (Wei \& Jiang 1993).

\section{Sampling and measurement methods}

Both lichen species were sampled on the surfaces of boulders along alpine trails

throughout the National park (Fig. 1). Boulders located under open sky conditions were randomly chosen if they had rock faces on which lichen individuals inhabited. To avoid the influence of volcanic gases, which strongly affect the distribution and growth of lichens (Shimizu 2004), we avoided boulders on which $U$. torrefacta was found. $U$. torrefacta is an index species found on volcanic and acidic boulders in this area (Shimizu 2004). Sampling was carried out with the permission of the Japanese Environmental Agency and the Agency for Cultural Affairs. We paid careful attention to preserve local populations of lichen species. For each rock face on the boulder where lichens were sampled, we measured elevation $(\mathrm{m})$, aspect $\left(0^{\circ}\right.$ to $360^{\circ}$ from N, clockwise, Fig. 2), inclination $\left(0^{\circ}\right.$ to $90^{\circ}$, Fig. 2$)$ and height above the ground $(\mathrm{cm})$. We sampled from all the rock faces on most boulders; the sampling number of individuals of various sizes per rock face was approximately ten. The sampling size was sufficient to estimate the random effects of rock faces and individuals as described in the statistical modeling subsection. However, on a few rock faces, we decreased the sample 
number per rock face to preserve local population. The dry weight (mg), surface area $\left(\mathrm{cm}^{2}\right)$, number of apothecia and maximum apothecium size of each sampled thallus were measured in the laboratory. The dry weight of each individual thallus was measured after drying the specimen for 1 week in a desiccator. The thallus surface area was measured using a 1-mm grid paper. Since thalli tended to be folded at the margins during specimen preparation, we divided the measured areas at folds and added these values together. The surface area was not the total area of each thallus but the light receptive surface area, particularly in the polyphyllous $U$. cylindrica. We counted the apothecia number under a $20^{\sim} 32$ magnification microscope with a hand-tally counter. We counted only apothecia exhibiting a disk margin. The maximum apothecium diameter on each thallus was measured with a micrometer under the same microscope.

\section{Evaluating sky openness on rock faces}

To evaluate sky openness for each rock face, we developed an index referred to as the sky openness index (SOI) that took into account both aspect and inclination (Fig. 2) of the rock face. The SOI for a rock face on a rock is a degree of shading on the rock face by the rock itself. The index was incorporated into the statistical model described below to estimate whether apothecium density increased or decreased on rock faces shaded by the focal rock itself, e.g., a steep rock face on the west side of a rock is shaded by the rock itself when the sun is in the east. 


\section{Statistical analysis}

A hierarchical Bayesian model was developed to estimate the effects of thallus area and the SOI on the number of apothecia taking into account the random effects of lichen individuals and rock faces. As Johnson (1999) discussed, most biological papers use tests of statistical significance that are, in fact, not significant at all. In the present study, the statistical model must take the random effects into account to be valid. It is, however, impossible to show how to construct a Bayesian model for all data in the paper. Therefore, we demonstrate the development and analysis of the Bayesian statistical model only to address the topic of interest, i.e., the observed number of apothecia.

We assumed that the number of apothecia of lichen individual $i$ and rock face $j, N_{i, j}$, followed the Poisson distribution of the mean $\lambda_{i, j}$ as follows:

$$
P\left\{x=N_{i, j}\right\}=\lambda_{i, j}^{x} \exp \left(-\lambda_{i, j}\right) / x !
$$

and the functional form of $\lambda_{i, j}$ was assumed as:

$$
\lambda_{i, j}=\exp \left(\beta_{B}\right) A_{i, j}^{\beta_{S}} S_{i}^{\beta_{S}}=\exp \left(\beta_{B}+\beta_{A} \log A_{i, j}+\beta_{S} \log S_{i}\right)
$$

where $\beta_{B}$ is the base density of apothecia; $A_{i, j}$ and $\beta_{A}$ are the thallus area (size) of individual $i$ on rock face $j$ and its exponent, respectively; and $S_{i}$ and $\beta_{S}$ are the estimated SOI on rock face $j$ and its exponent, respectively. The random effects of lichen individuals and rock faces were incorporated into the base density, thus the base density parameter $\beta_{B}$ is divided as $\beta_{B}=\beta_{0}+\gamma_{i}+\gamma_{j}$, where $\beta_{0}$ is the constant portion of apothecium density, and $\gamma_{i}$ and $\gamma_{j}$ are the random effects of lichen individual $i$ and rock face $j$, respectively. The random effects, which 
represent unobservable effects of individual attributes and characteristics of rock faces, are incorporated as random variables in the linear predictor. This means that the median of the distribution of the number of apothecia is not changed but its variance is (Crawley, 2005). One of the important roles of the parameters for random effects is the modeling of overdispersion (Crawley 2005). In modeling of apothecium density, overdispersion causes the estimate of the variance of the number of apothecia to be much larger than the expected estimate under a Poisson distribution. The overdispersed distribution of the apothecium number can be expressed by the convolution of the Poisson distribution and the normal distributions characterized by the random effect parameters in the model. Another role of the random effect parameters is the representation of the nuisance parameters such as elevation, microtopography around boulders and rock faces, and other unobservable/unobserved factors. This is particularly important in pseudoreplication situations where multiple samples (e.g. lichen individuals) are obtained from the same block (e.g. a rock face). Statistical analysis including random effects allows the effects of pseudoreplication to be taken into account (Crawley 2005).

The fixed effect parameters, $\beta_{0}, \beta_{A}$, and $\beta_{S}$ were estimated independently for $U$. cylindrica and L. pensylvanica. The random effect of rock face $j, \gamma_{j}$, was assumed to be common to both species. As the number of parameters is too large for the maximum likelihood method to be used, we adopted a hierarchical Bayesian approach in which all parameters were 
expressed as posterior distributions estimated from a combination of observed data and prior distributions (e.g. Clark \& Gelfand 2006). The prior distributions used in the current model are shown in Table 1. An advantage of a hierarchical Bayesian modeling is that it overcomes the technical difficulties of the maximum likelihood estimation for a relatively large number of parameters. This is because we use direct sampling of posterior distributions of parameters (e.g. Clark \& Gelfand 2006) based on a given data set and a set of prior and hyperprior distributions. Another advantage is that prior distributions are also dynamically generated from appropriate non-informative hyperpriors to obtain better fits for the data.

Sampling from the posterior distributions of the parameters using Markov Chain Monte Carlo (MCMC) methods was performed with WinBUGS 1.4.2 (Spiegelhalter et al. 2003) in the R2WinBUGS package (Sturtz et al. 2005) in R 2.4.1 (R Development Core Team 2006). The posterior samples were obtained from three independent Markov chains in which 300 values were sampled with a 100 iteration interval after a burn-in of 30000 iterations. The convergence of the Markov chains was evaluated with $\hat{R}$ (Gelman et al. 2003) for each parameter by comparing the variance within each chain and among chains. All source code files were written in R and BUGS languages and the entire data set used in the current estimation can be downloaded from http://hosho.ees.hokudai.ac.jp/ kubo/r/lichen/. 


\section{Results}

A total of 396 thalli of $U$. cylindrica were collected from 38 rock faces of 18 boulders, and 222 thalli of $L$. pensylvanica were collected from 25 rock faces of 13 boulders. In $U$. cylindrica, the mean thallus surface area and mean thallus weight were $4.12 \mathrm{~cm}^{2}$ (range 0.480-26.2 $\left.\mathrm{cm}^{2}\right)$ and $217 \mathrm{mg}$ (range 8.00-1790 $\mathrm{mg}$ ), respectively, whereas those for $L$. pensylvanica were $5.92 \mathrm{~cm}^{2}\left(0.74-20.1 \mathrm{~cm}^{2}\right)$ and $320 \mathrm{mg}$ (12.0-1390 mg), respectively. The allometric relationships between the thallus area and weight for each species are shown in Fig. 3 A and B. Although we did not apply detailed Bayesian modeling to analyze the relationships, we can make two conclusions about the relationships: First, the set of the log of thallus area and weight is not a random sample from the bivariate normal distribution for which covariance elements are considerably positive. Second, there is no great difference in the allometric exponent between two species in the log-log plot. In other words, the thallus mass per area $\left(\mathrm{mg} \mathrm{cm}^{-2}\right)$, depending on thallus area, could resemble each other; whereas, the variance of density increased for both species when the thallus area increased (Fig. $3 \mathrm{C}$ and D).

The mean number of apothecia increased as thallus area increased (Fig. 4A). Umbilicaria cylindrica produced many apothecia on smaller thalli, whereas $L$. pensylvanica produced fewer late developing apothecia on larger thalli. The mean number of apothecia per thallus and mean maximum apothecium size per thallus for U. cylindrica were 88.2 (range 0-903) and $1.25 \mathrm{~mm}$ (range 0.220-2.18 mm), respectively, whereas those in $L$. pensylvanica were $15.2(0-321)$ and $1.59 \mathrm{~mm}$ 
$(0.300-3.33 \mathrm{~mm})$, respectively. The relationships between the SOI and the number of apothecia for the two species are shown in the Fig. 4 B. Since the thallus size reliably predicted the number of apothecia, the effects of the SOI and the differences between the two species appeared to be hidden by the effects of the differences in thallus size between the lichens. The curves in Fig. 4 B, however, indicate the effects of the SOI on the mean number of apothecia under mean thallus size. These are based on the posterior distributions of the parameters of the hierarchical Bayesian model, which are described later.

We prepared Fig. 5 to demonstrate the difficulties in predicting the number of apothecia using simple regression analyses of these measurements, i.e., elevations, aspects, inclinations and heights of rock faces, because the data were heteroscedastic for continuous measurements and were overdispersed for countable measurements. Aspects and inclinations of rock faces were used in the evaluation of the SOI, whereas elevation and height represented some of the random effects of rock faces, $\gamma_{i}$. The median of the variance parameters of the random effects derived from rock faces, $\gamma_{i}$, and lichen individuals, $\gamma_{j}$, were 1.01 and 1.25 , respectively (Table 2 ).

The distribution of thalli on the boulders is shown in Fig. 6 where the SOI distribution is indicated by shading. Since the rock face inclination becomes smaller near the center of each figure, the SOI values increase towards the center. The SOI values on inclined rock faces did not differ greatly with aspect. Both species were found in various SOI environments. However, in U. cylindrica (Fig. 
$6 \mathrm{~A})$, the distribution of sampled thalli was not random, although there was no method to characterized the distribution. For L. pensylvanica (Fig. 6B), we could not examine whether the distribution was random or not because the number of samples was too small. The relationship between the SOI and apothecium density (diameter of each species circle in Fig. 6) was obscure in both species.

The estimates or parameters in the hierarchical Bayesian model based on apothecium number are listed in Table 2 and Fig. 7. All $\hat{R}$ estimates for parameters were so close to unity that the Markov chains for all fixed and random effect parameters were sufficiently converged. The medians of posteriors of all fixed effect parameters $\left(\beta_{0}, \beta_{A}\right.$, and $\left.\beta_{S}\right)$ for $U$. cylindrica were larger than those of $L$. pensylvanica. The medians of the exponent of thallus area, $\beta_{A}$, were 1.82 and 1.52 for $U$. cylindrica and L. pensylvanica, respectively, significantly larger than unity. Most samples obtained from the posterior distribution of the SOI effect on apothecium density, $\beta_{S}$, for $U$. cylindrica were positive (median $\beta_{S}=0.54$, Table 2 and Fig. 7), but the 95\% confidence interval [-0.04, 1.09] included zero. On the other hand, the medians of the posterior $\beta_{S}$ for L. pensylvanica were almost zero. (median $\beta_{S}=0.03$, Table 2 and Fig. 7). In short, we determined that the apothecium density of $U$. cylindrica depended on thallus size and, possibly, on the SOI, while that of L. pensylvanica depended only on thallus size.

\section{Discussion}

We demonstrated differences in the relationship between the number of apothecia and thallus area between a pair of sympatric lichens, $U$. cylindrica and $L$. 
pensylvanica, using a new statistical model for apothecium density. The model suggested that there may be species-specific responses to light conditions on rock faces. These results were based on hierarchical Bayesian modeling taking into account the effects of nuisance factors or the unobserved factors of rock faces and individual lichens.

By evaluating the posterior distributions of $\beta_{A}$ (Table 2 and Fig. 7), we concluded that the relationships between thallus area and the number of apothecia were allometric rather than isometric for both species. This was because the exponents of the log of thallus area were significantly larger than unity, i.e., apothecium density increased when the thallus area increased. Our results regarding the modeling of the apothecium density support exponential (Pringle et al. 2003) and allometric (Jackson et al. 2006) rather than linear formulation (Ramstad and Hestmark 2001).

Statistical analysis in the present study detected large random effects derived from rock faces and lichen individuals (Table 2). We propose that Bayesian modeling, which takes into account these random or nuisance factors, is required to properly estimate fixed effects such as thallus area and the SOI in statistical analyses of field data. In the mixed modeling of fixed and random effects, the parameters of random effects were assumed to include the effects of elevation and height of rock faces (Fig. 5).

We detected a difference between two sympatric lichens in the response of apothecium density both to thallus area and the SOI. As shown in Fig. 4 A, the 
response of the apothecium number to thallus area was much more sensitive in $U$. cylindrica than in L. pensylvanica because of differences between these two species in the log of base apothecium density, $\beta_{0}$, and the exponent of thallus area, $\beta_{A}$ (Table 2 and Fig. 7). However, it is difficult to assess the reproductive allocation for these lichens because their apothecium sizes differ. The apothecia of $U$. cylindrica, which has higher apothecium density, are smaller than those of $L$. pensylvanica, which has lower apothecium density. Therefore, we discuss only the response of the apothecium number to thallus area and the SOI.

There are several possible physiological explanations for the positive relationship between apothecium density and thallus area we observed. Dahlman and Palmqvist (2003) suggested that thallus growth in two foliose tripartite lichens was influenced by greater water-holding capacity. Although we did not measure water relationships, we believe that an advantage of a large thallus is a higher water-holding ability. This is consistent with Gauslaa and Solhaug (1998) who reported differences in the desiccation rate depending on the thallus area. They concluded that the improved water-holding capacity in larger thalli was mainly a result of a thicker hypothallus. In the umbilicate lichens at our research site, a greater ability to retain water during desiccation may increase as the thallus area increases because the mean thallus mass per unit area $\left(\mathrm{mg} \mathrm{cm}^{-2}\right)$ tends to increase when thallus area is large (Fig. $3 \mathrm{C}$ and D). Umbilicate lichen thalli generally have rather high water holding capacities and high tolerance to osmotic stress (Harrissson et al. 1989; Hájek et al. 2006). There are also lichens 
sensitive to thallus desiccation that maximizes their photosynthetic rate in dim light (e.g. Lange 2003; Gauslaa et al. 2006).

Before discussing the light response of lichens, we describe biological interpretations of the effects of the SOI as we defined for this study. The SOI indicates the sky openness is weighted by the solar trajectory or the lack of local shading from the same boulder. It does not indicate cumulative irradiance because the daily change of solar radiation is not incorporated. Although Dahlman and Palmqvist (2003) stressed the importance for thallus growth of light intensity under wet conditions, we did not define the SOI as such a conditional index. This is because of the highly unpredictable hydration regime at the alpine research site. The boulders in the alpine area are frequently hydrated by mists or condensation during daytime in summer, while thalli can be desiccated even in the early morning.

The response of the number of apothecia to the SOI, $\beta_{S}$, differed between the two species (Table 2, Fig. 4 B, and Fig. 7). However, both species were distributed on rock faces with various SOI levels (Fig. 6). The apothecium density of $U$. cylindrica probably increased on unshaded rock faces whereas that of $L$. pensylvanica did not respond to the SOI. It is important that the SOI is an explanatory variable of apothecium density despite its very simplified definition as an index of the sky openness. This result indicated that $U$. cylindrica increases photosynthetic rate as the SOI increases. Species differences in plasticity are possibly caused by differences in the maximum photosynthetic rate or 
water-holding capacity. In other words, L. pensylvanica may be sensitive to the negative effects of the SOI such as photoinhibition and desiccation. However, we found no evidence of negative effects from evaluating the posterior distribution of $\beta_{s}$.

\section{Acknowledgment}

The authors are grateful to two anonymous reviewers for their helpful comments. 


\section{Appendix: Modeling of sky openness}

The coordinate system used in sky openness index (SOI) modeling is shown in Fig. 2 in which the $x$ and $y$ axes correspond to west-east and north-south axes, respectively. In the coordinate system, all vectors are defined as follows:

$$
\vec{v}=\{\cos \theta \cos \phi, \sin \theta \cos \phi, \sin \phi\}=\left\{v_{x}, v_{y}, v_{z}\right\}
$$

and are always normalized (i.e. $v_{x}+v_{y}+v_{z}=1$ ). Hence, the normal vector of a rock face $\vec{f}$ is defined using measurements of aspect and the inclination of the rock face:

$$
\vec{f}=\left\{\cos \theta_{f} \cos \phi_{f}, \sin \theta_{f} \cos \phi_{f}, \sin \phi_{f}\right\}
$$

where both $\theta_{f}$ and $\phi_{f}$ are converted from the aspect $(d)$ and inclination $(g)$ of the rock face so that $\theta_{f}=0.5 \pi-d$ and $\phi_{f}=0.5 \pi-g$. Note that the unit of angle in the coordinate system is radians.

In the model, time $t$ in a day is defined as an angle, the range of $t$ is from $-0.5 \bullet$ to $1.5 \bullet$ Giving some examples of time angles, $t=\{-0.5 \bullet, 0.5 \bullet, \bullet\}$ correspond to midnight, noon, and $6 \mathrm{pm}$, respectively. By using the time angle, the direction vector of the sun at time $t$ is defined as:

$$
\vec{s}=\left\{\cos \theta_{s}(t) \cos \phi_{s}(t), \sin \theta_{s}(t) \cos \phi_{s}(t), \sin \phi_{s}(t)\right\}
$$

The day of the year is also expressed by angle $a_{d}$ in the range $[-0.13 \bullet$, $0.13 \bullet]$. For example, $a_{d}=0$ for spring and autumn equinox days and $a_{d}=0.13 \bullet$ (equal to the rotation angle of the axis of the earth) for the summer solstice day. Suppose $\vec{s}_{e}(t)$ is the direction vector of the ecliptic observed on the equator at 
time $t$. The elements of the vector are $\left\{r \cos t, y_{e}, r \sin t\right\}$ where $y_{e}=\cos a_{d}$ and $r=\sqrt{1-y_{e}^{2}}$. The ecliptic vector observed from latitude $L \mathrm{~N}, \vec{s}_{L}(t)$, can be derived by transforming $\vec{s}_{e}(t)$. By setting $\vec{s}_{e}(t)=\left\{e_{x}, e_{y}, e_{z}\right\}$, the elements of $\vec{s}_{e}(t)$ are derived as: $\left\{e_{x}, r_{y, z} \cos \theta_{L}, r_{y, z} \sin \theta_{L}\right\}$ where $r_{y, z}=\sqrt{e_{y}^{2}+e_{z}^{2}}$ and $\theta_{L}=\arccos \left(e_{y} / r_{y, z}\right)+L$ (if $a_{d}>0$ ).

Suppose the angle between the rock face and the sun, $\bullet(t)$, is derived as follows:

$$
\cos \alpha(t)=\vec{f} * \vec{s}_{L}(t)
$$

where $\vec{f}$ is the normal vector of a rock face, $\vec{s}_{L}(t)$ is the sun direction, and the binary operator " $a * b$ " generates the inner product of $a$ and $b$. Note that both $\vec{f}$ and a $\vec{s}_{L}(t)$ are normalized. Since the $\cos \bullet(t)$ does not include the daily change of the intensity of solar irradiance, the SOI is defined as the sum of the total exposure time of the rock face weighted by solar trajectory, that is:

$$
\mathrm{SOI}=\int_{-0.5 \pi}^{1.5 \pi} w_{s}\left(s_{L}(t)\right) w_{\alpha}(\alpha(t)) d t
$$

where $w_{s}\left(s_{L}(t)\right)$ is a function that is unity if the sun is over the horizon (i.e. $s_{L}(t)$ $>0$, daytime), otherwise zero; $w_{\alpha}(\alpha(t))$ is defined as $\cos \alpha(t)$ if $0 \leq \alpha(t) \leq 0.5 \pi$, otherwise zero because the sun cannot be seen from the rock face when it is behind it. We evaluated SOIs for all observed rock faces by fixing ad $=0.13 \pi$ (the summer solstice day) and $\mathrm{L}=0.239 \pi$ (latitude $43^{\circ} \mathrm{N}$ ) for the appropriate model for lichen growth in the area. 


\section{References}

Armstrong, R. A. (1975) The influence of aspect on the pattern of seasonal growth in the lichen Parmelia glabratula ssp. fuliginosa (Fr. ex Duby) Laund. New Phytologist 75: 245-251.

Armstrong, R. A. (2002) The effect of rock surface aspect on growth, size structure and competition in the lichen Rhizocarpon geographicum. Environmental and Experimental Botany 48: 187-194.

Clark, J.S., Mohan, J., Dietze, M., \& Ibanez, I. (2003) Coexistence: How to identify trophic trade-offs. Ecology 84: 17-31.

Clark, J.S. \& Gelfand, A. (2006) Hierarchical modelling for the environmental sciences: statistical methods and applications. Oxford: Oxford University Press.

Crawley, M. J. (2005) Statistics: An Introduction Using R. West Sussex: John Wiley and Sons.

Dahlman, L. \& Palmqvist, K. (2003) Growth in two foliose tripartite lichens, Nephroma arcticum and Peltigera aphthosa: empirical modelling of external vs internal factors. Functional Ecology 17: 821-831.

de Jong, T. \& Klinkhamer, P. (2005) Evolutionary ecology of plant reproductive strategies. Cambridge: Cambridge University Press.

Gauslaa, Y., Lie, M., Solhaug, K. A. \& Ohlson, M. (2006) Growth and ecophysiological acclimation of the foliose lichen Lobaria pulmonaria in forests with contrasting light climates. Oecologia 147:406-416. 
Gauslaa, Y. \& Solhaug, K. A. (1998) The significance of thallus size for the water economy of the cyanobacterial old-forest lichen Degelia plumbea. Oecologia 116: $76-84$.

Gelman, A., Carlin, J.B., Stern, H.S. \& Rubin, D.B. (2003) Bayesian Data Analysis (2nd ed.). Boca Raton: Chapman \& Hall/CRC.

Hájek, J., Barták, M. \& Dubová, J. (2006) Inhibition of photosynthetic processes in foliose lichens induced by temperature and osmotic stress. Biologia Plantarum 50(4): 624-634.

Harrison, P. M., Walton, D. W. H. \& Rothery, P. (1989) The effects of temperature and moisture on $\mathrm{CO}_{2}$ uptake and total resistance to water loss in the Antarctic foliose lichen Umbilicaria antarctica. New Phytologist 111: 673-682.

Jackson, H. B., Clair, L. S. St. \& Eggett, D. L. (2006) Size is not a reliable measure of sexual fecundity in two species of lichenized fungi. Bryologist 109: 157-165.

Johnson, D. (1999) The insignificance of statistical significance testing. Journal of Wildlife Management 63:763-772.

Katsui, Y., Takahashi, T. \& Doi, S. (1953) The geological sheet map "Tokachidake", scale 1: 50,000, and its explanatory text: Hokkaido Development Agency, in Japanese with English abstract.

Kurokawa, S. (2006) Phytogeographical elements of the lichen flora of Japan. Journal of the Hattori Botanical Laboratory 100: 721-738.

Lange, O. L. (2003) Photosynthetic productivity of the epilithic lichen Lecanora muralis: long-term field monitoring of $\mathrm{CO}_{2}$ exchange and its physiological 
interpretation: II. Diel and seasonal patterns of net Photosynthesis and respiration. Flora 198: 55-70.

Larson, D. W. (1984) Thallus size as a complicating factor in the physiological ecology of lichens. New Phytologist 97: 87-97.

Monte, M. (1993) The influence of environmental conditions on the reproduction and distribution of epilithic lichens. Aerobiologia 9: 169-179.

Pringle, A., Chen, D. \& Taylor, J. W. (2003) Sexual Fecundity is correlated to size in the lichenized fungus Xanthoparmelia cumberlandia. Bryologist 106: $221-225$

R Development Core Team (2006). $R:$ A language and environment for statistical computing. Vienna: R Foundation for Statistical Computing.

Ramstad, S. \& Hestmark, G. (2001) Population structure and size-dependent reproductive effort in Umbilicaria spodochroa. Mycologia 93: 453-458.

Reekie, E.G. \& Bazzaz, F.A. 2005. Reproductive allocation in plants. London: Academic press.

Sancho, L. G. \& Kappen, L. (1989) Photosynthesis and water relations and the role of anatomy in Umbilicariaceae (lichens) from Central Spain. Oecologia 81: $473-480$

Shimizu, A., Inoue, M. and Moon, K. H. (2004) Lichen flora of Mt. Tokachi, Hokkaido, Japan. Bulletin of National Science Museum, Tokyo, Series B, 30: 89-102.

Shimizu, A. (2004) Community structure of lichens in the volcanic highlands of 
Mt. Tokachi, Hokkaido, Japan. Bryologist 107: 141-151.

Spiegelhalter, D.J., Thomas, A. \& Best, N.G. (2003) WinBUGS 1.4. Cambridge: Imperial College \& MRC Biostatistics Unit.

Sturtz, S., Ligges, U. \& Gelman, A. (2005) R2WinBUGS: A Package for Running WinBUGS from R. Journal of Statistical Software 12:1-16.

Valladares, F., Ascaso, C. \& Sancho, L. G. (1993) Intrathalline variability of some structural and physical parameters in the lichen genus Lasallia. Canadian Journal of Botany 72: 415-428.

Wei, J. \& Jiang, Y. (1993) The Asian Umbilicariaceae. Mycosystema Monographicum Series No.1. Beijing: International Academic Publishers. 


\section{Figure Legends}

FIG. 1. Location of the study area with 31 sampled boulders in the Daisetsuzan National Park, Hokkaido, Japan. A total of 396 specimens of Umbilicaria cylindrica were collected from 38 rock faces at 18 sites (circles), and 222 specimens of Lasallia pensylvanica were collected from 25 rock faces at 13 sites (triangles).

FIG. 2. The coordinate system used for SOI modeling. The $x$ and $y$ axes correspond to west-east and south-north axes, respectively.

FIG. 3. Relationship between thallus surface area and thallus weight in (A) Umbilicaria cylindrica (circles) and (B) Lasallia pensylvanica (triangles). Relationship between thallus surface area and thallus mass per area (weight / area) in (C) Umbilicaria cylindrica (circles) and (D) Lasallia pensylvanica (triangles). The $x$ and $y$ axes are log transformed.

FIG. 4. Relationship between the number of apothecia and (A) thallus surface area (cm2, in log scale) and (B) the estimated sky openness index, SOI, in Umbilicaria cylindrica (circles) and Lasallia pensylvanica (triangles). The $x$ and $y$ axes are log and square root transformed, respectively. The curves are the prediction of mean apothecium number by fixing the SOI in (A) and thallus area (B) to their population mean values, respectively.

FIG. 5. Scatter diagrams of environmental factors and thallus surface area, number of apothecia, and apothecia density. Environmental factors are elevation (m), aspect of the rock face $\left(0^{\circ}\right.$ to $360^{\circ}$ from $\mathrm{N}$, clockwise), inclination of the rock 
face $\left(0^{\circ}\right.$ to $\left.90^{\circ}\right)$ and height above the ground $(\mathrm{cm})$.

FIG. 6. Thallus distributions of Umbilicaria cylindrica (A) and Lasallia pensylvanica (B) in relationship to aspect and inclination of the rock face on boulders. Each concentric circle indicates thalli collected from the same rock face; the center of each circle indicates aspect ( $0^{\circ}$ to $360^{\circ}$ from $\mathrm{N}$, clockwise) and inclination $\left(0^{\circ}\right.$ to $\left.90^{\circ}\right)$ of the sampled rock face. The radius of each circle is proportional to the apothecium density of each thallus. The shading becomes darker as the SOI value decreases. The range of SOI values evaluated on all possible rock faces was 0.158-0.568.

FIG. 7. Traces of the Markov chains and the posterior densities of the fixed effect parameters in the hierarchical Bayesian analysis. 
TABLE 1 The definitions of prior distributions of parameters. The 'distribution' column shows the name of the probabilistic distribution used as the prior distribution for each parameter. The 'mean' and 'variances' columns show the means and variances of the posterior distribution, respectively.

\begin{tabular}{rlccc}
\hline & \multicolumn{1}{c}{ parameter } & distribution & mean & variance \\
\hline$N_{i, j}$ & number of apothecia & Poisson & $\lambda_{i, j}$ & $\lambda_{i, j}$ \\
$\beta_{0}$ & apothecia density (fixed effects) & Gaussian & 0 & $10^{2}$ \\
$\beta_{A}$ & thalli area (fixed effects) & Gaussian & 0 & $10^{2}$ \\
$\beta_{S}$ & SOI (fixed effects) & Gaussian & 0 & $10^{2}$ \\
$\gamma_{i}$ & apothecia density & Gaussian & 0 & $1 / \tau_{\gamma_{i}}$ \\
& (random effects of lichen) & Gaussian & 0 & $1 / \tau_{\gamma_{j}}$ \\
$\gamma_{j}$ & apothecia density & Gandom effects of rock face) & 1 & $10^{2}$ \\
$\tau_{\gamma_{i}}$ & variance parameter of $\gamma_{i}$ prior & Gamma & 1 & $10^{2}$ \\
$\tau_{\gamma_{j}}$ & variance parameter of $\gamma_{j}$ prior & Gamma & 1 &
\end{tabular}


TABLE 2 The posterior distributions of parameters of fixed effects and variances. The quantiles $(2.5 \%, 50 \%$, and $97.5 \%)$ of posterior distributions are shown.

\begin{tabular}{crrrrrr}
\hline & \multicolumn{3}{c}{ Umbilicaria cylindrica } & \multicolumn{3}{c}{ Lasallia pensylvanica } \\
parameter & $2.5 \%$ & $50.0 \%$ & $97.5 \%$ & $2.5 \%$ & $50.0 \%$ & $97.5 \%$ \\
\hline$\beta_{0}$ & 1.01 & 1.45 & 1.93 & -1.64 & -0.84 & -0.04 \\
$\beta_{A}$ & 1.61 & 1.82 & 2.04 & 1.23 & 1.53 & 1.86 \\
$\beta_{S}$ & -0.04 & 0.54 & 1.09 & -0.75 & 0.03 & 0.86 \\
\hline
\end{tabular}

\begin{tabular}{crrr}
\hline & \multicolumn{3}{c}{ (common parameter) } \\
parameter & $2.5 \%$ & $50.0 \%$ & $97.5 \%$ \\
\hline$\tau_{i}$ & 0.82 & 1.25 & 1.93 \\
$\tau_{j}$ & 0.86 & 1.01 & 1.19 \\
\hline
\end{tabular}


FIG. 1

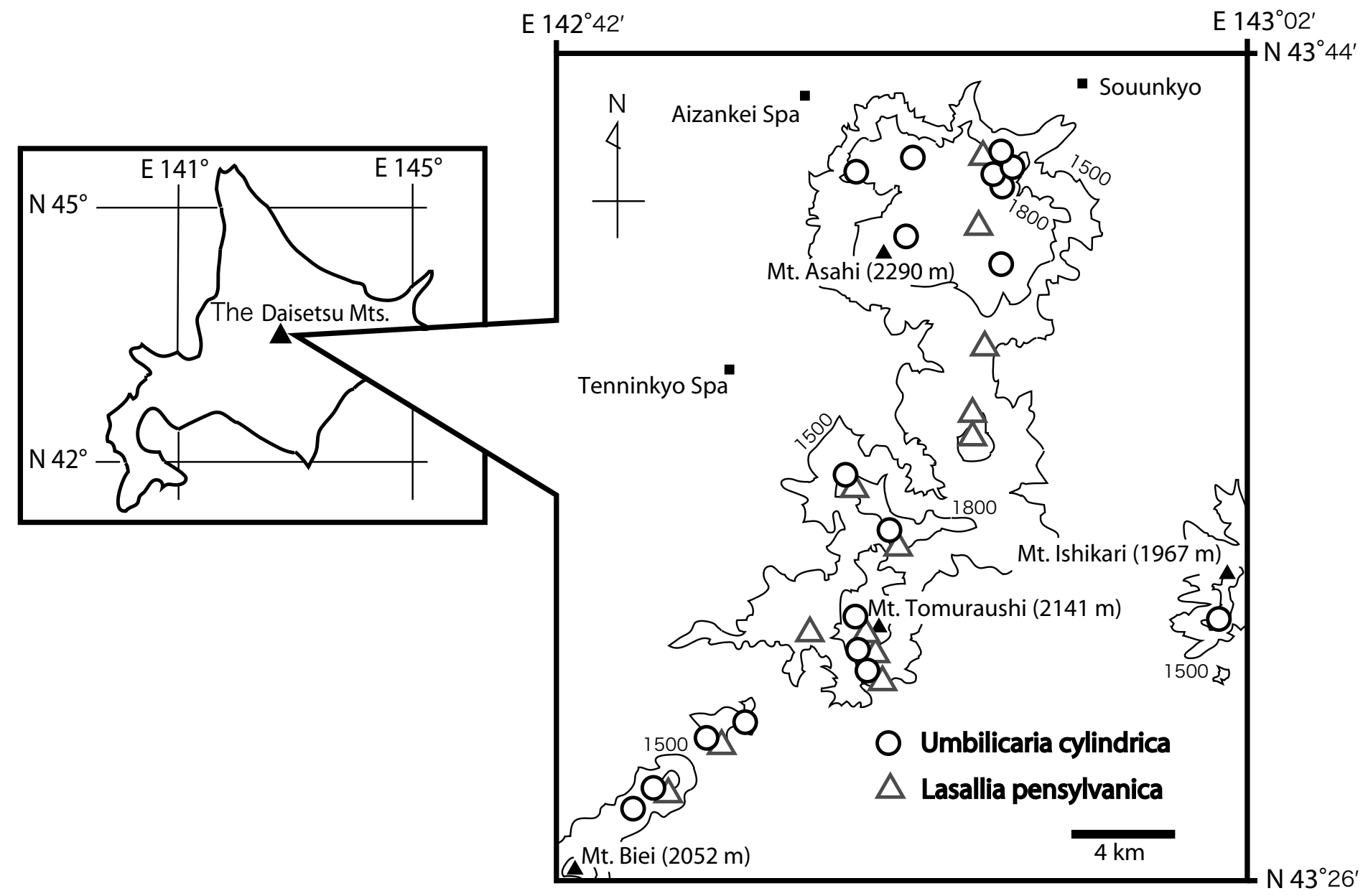


FIG. 2

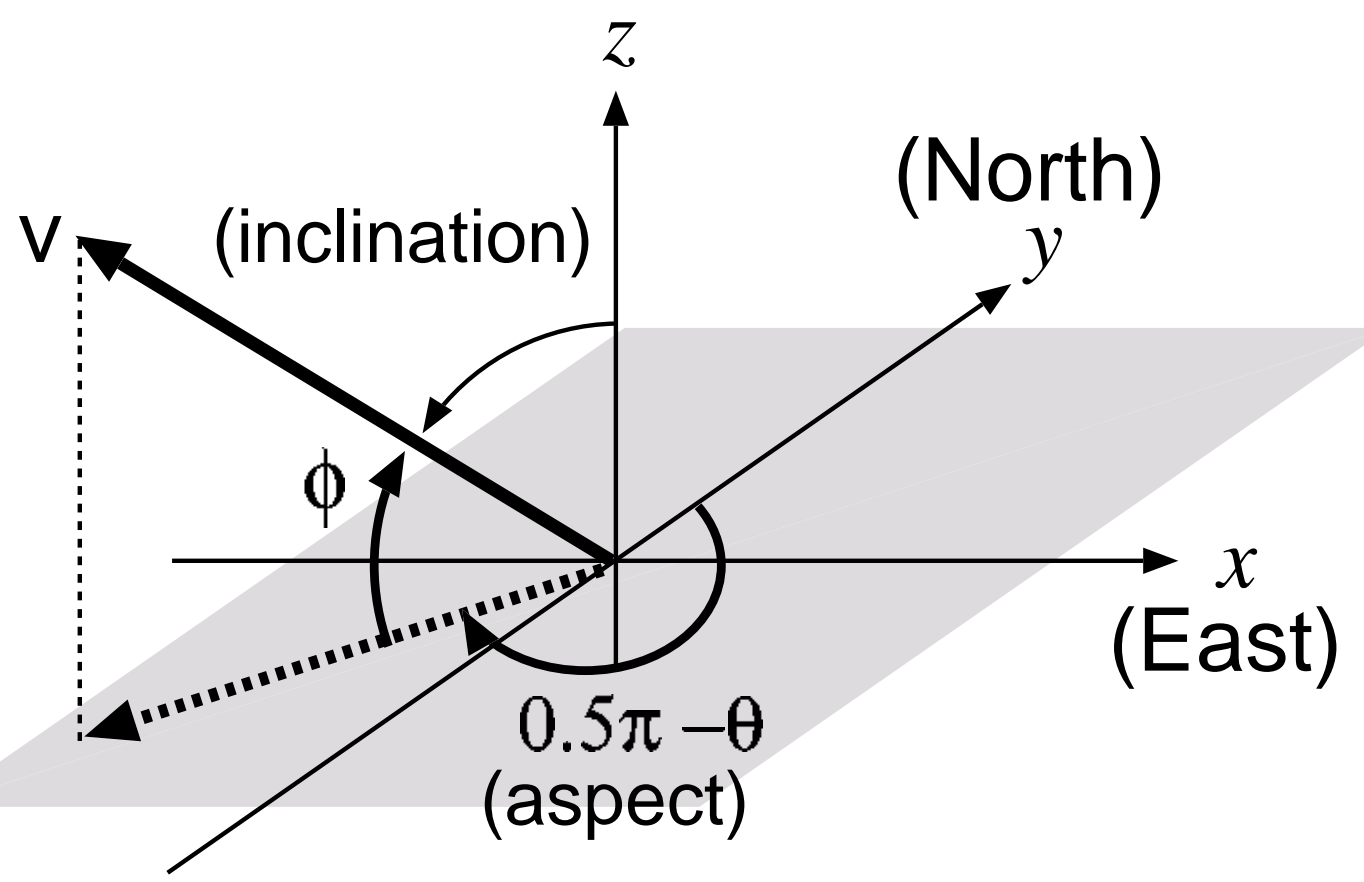


FIG. 3

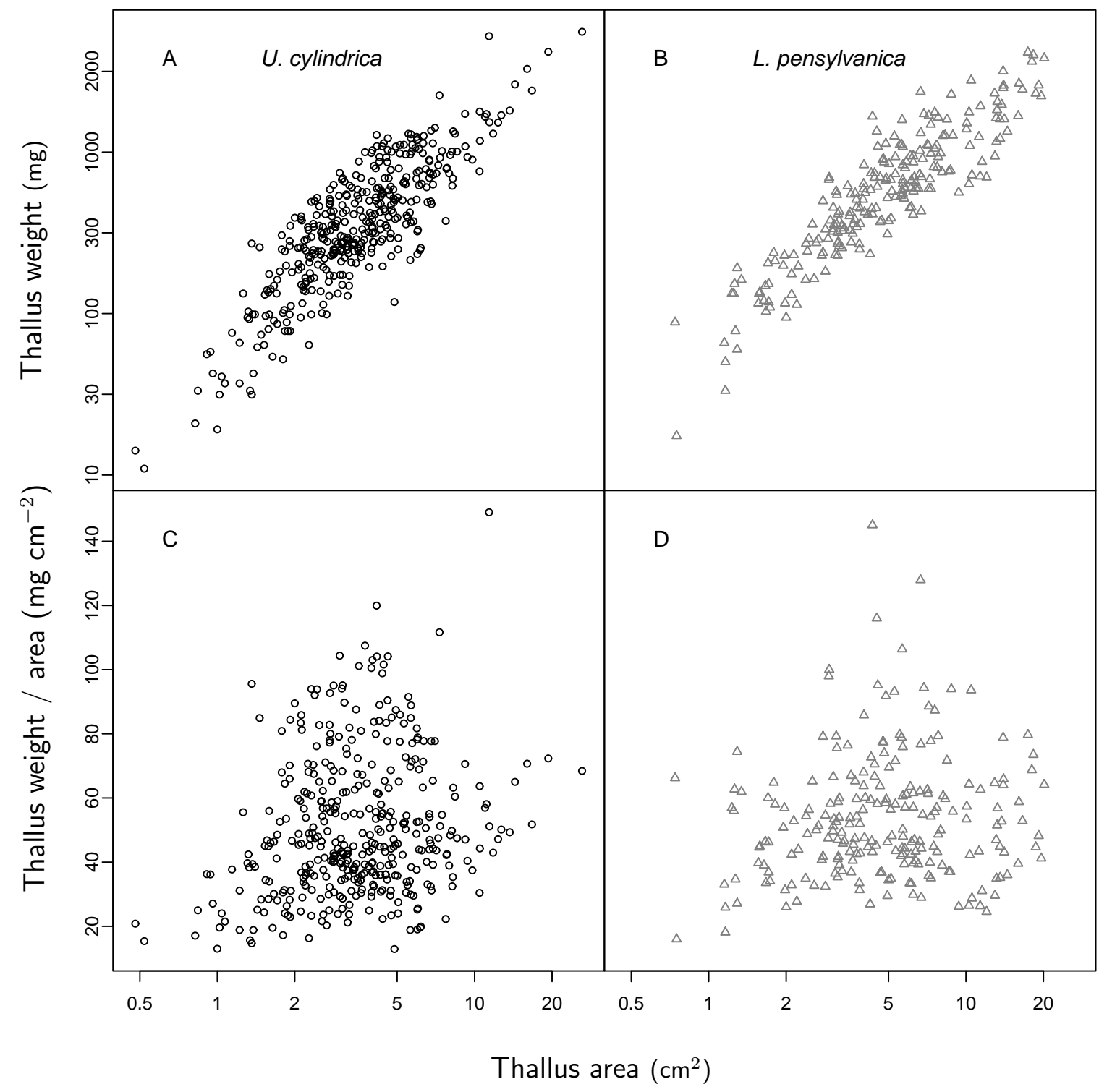


FIG. 4

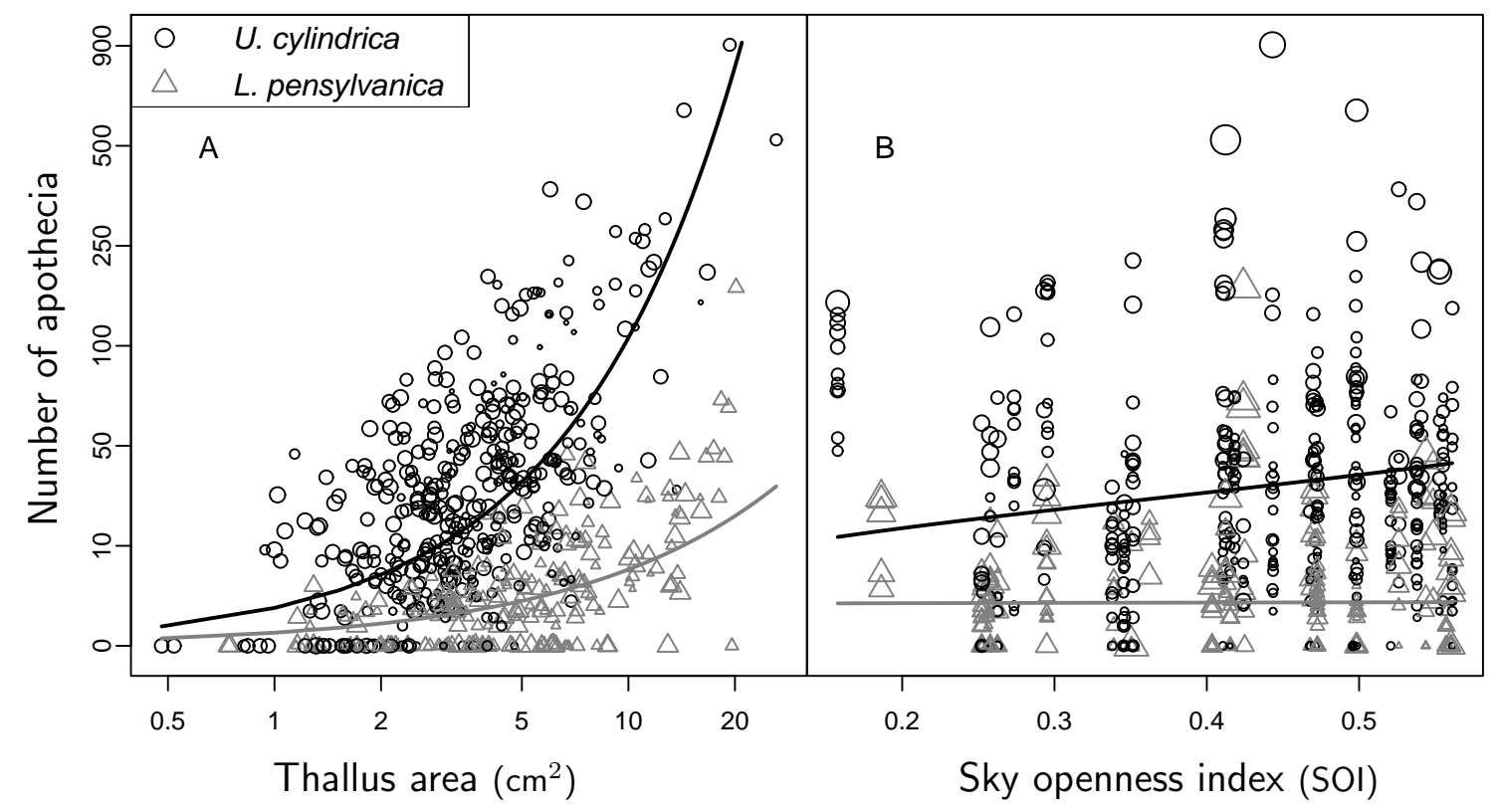


FIG. 5

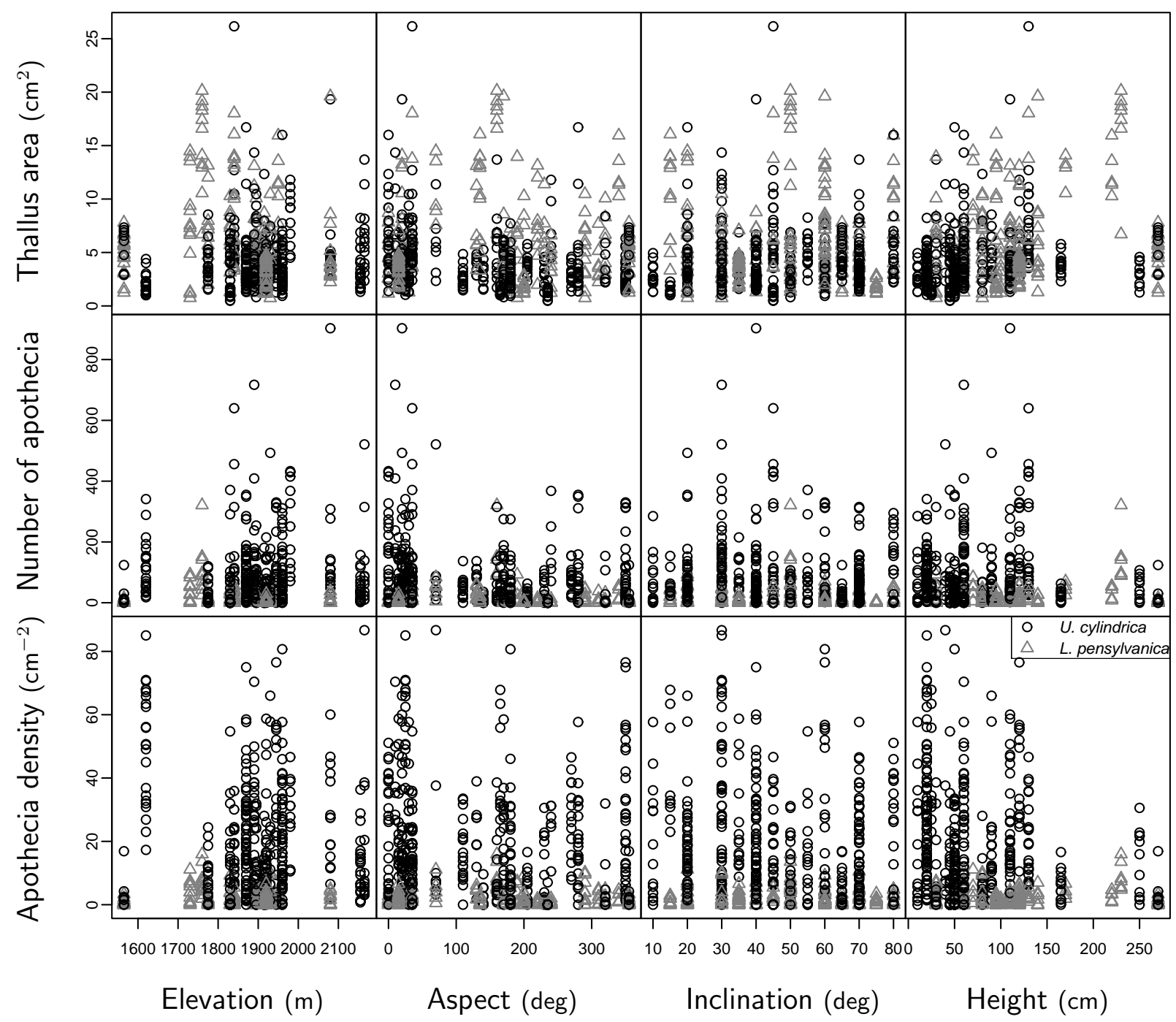


FIG. 6A

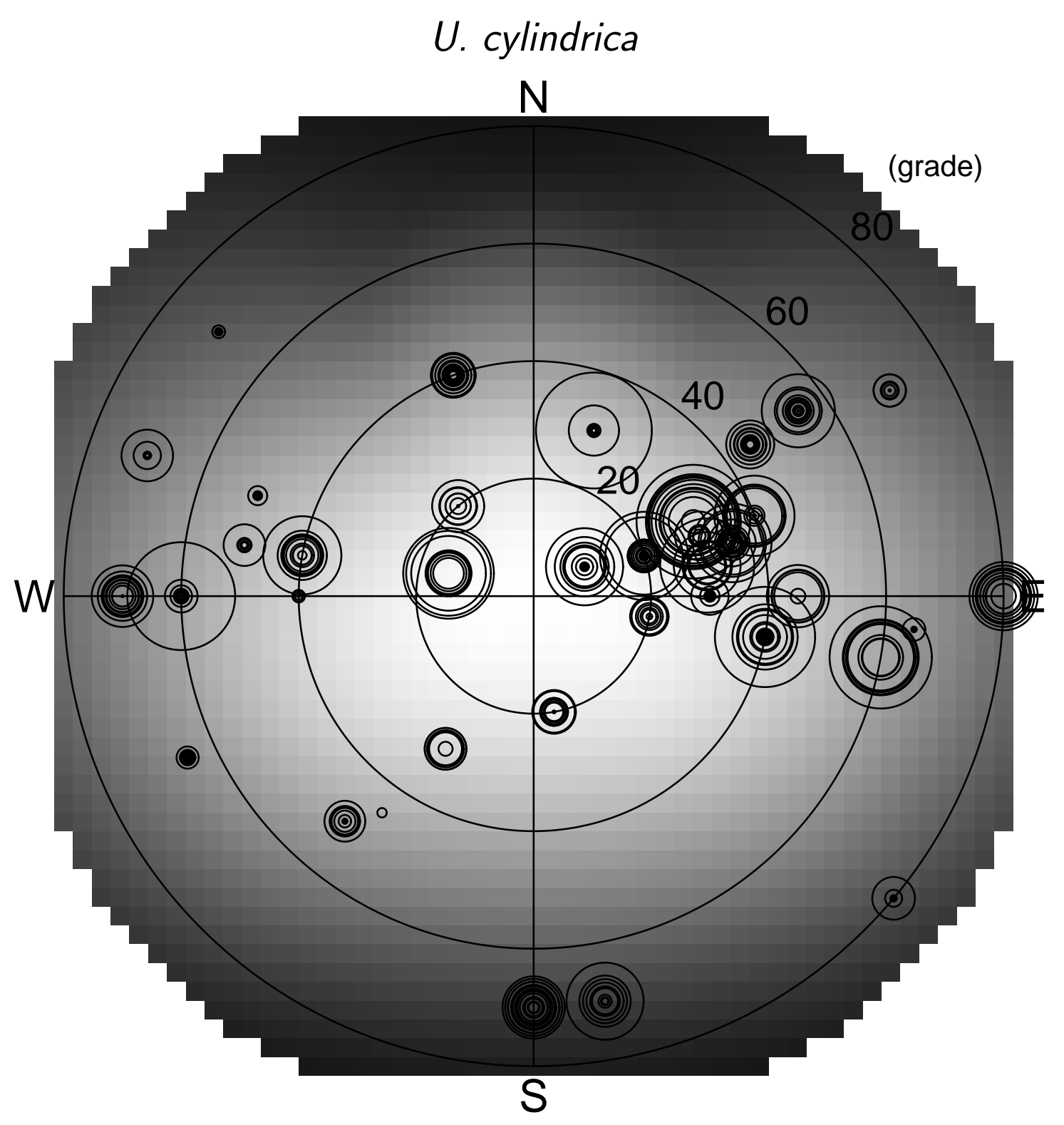


FIG. 6B

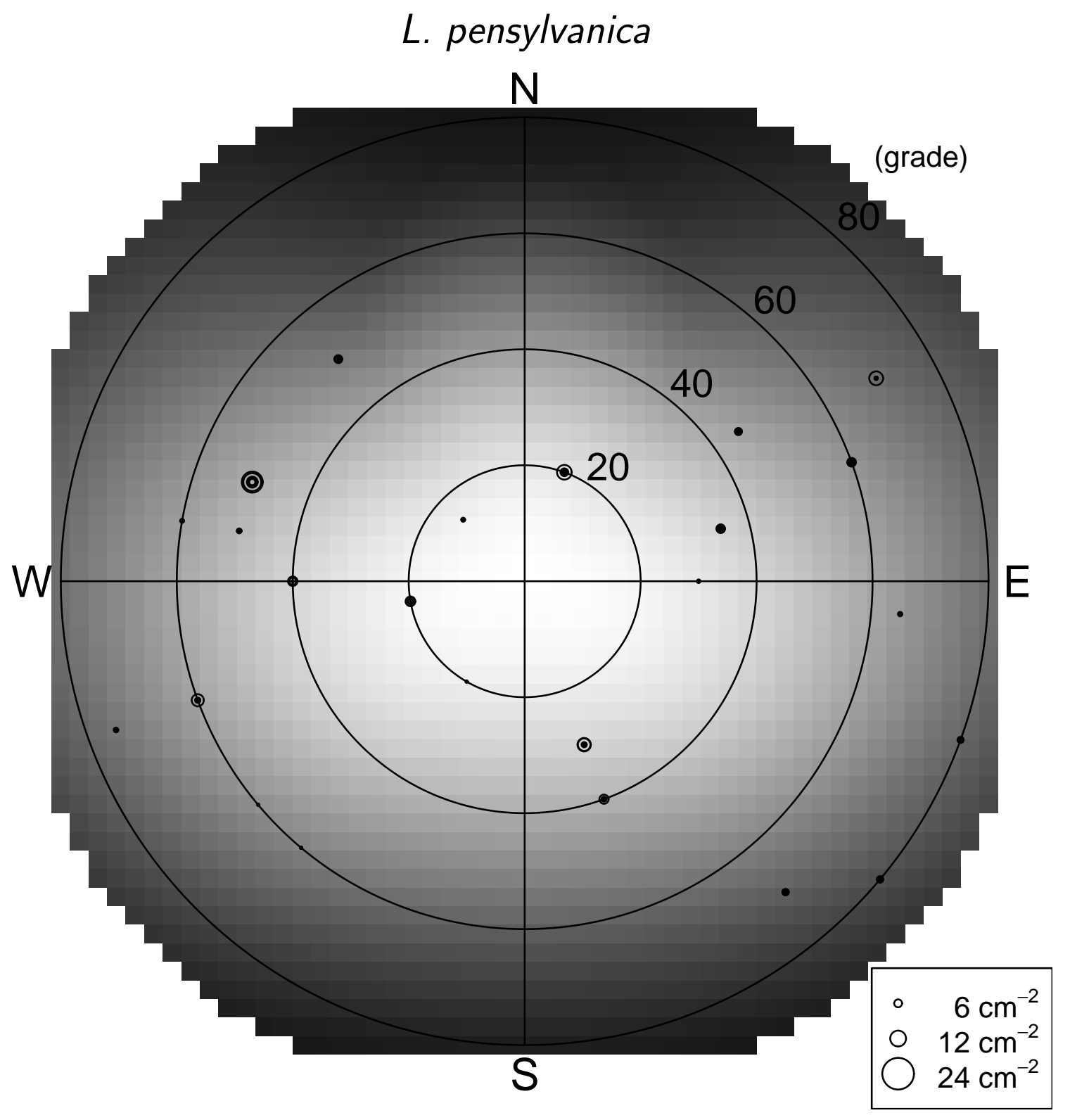


FIG. 7

Parameter trace for

U. cylindrica
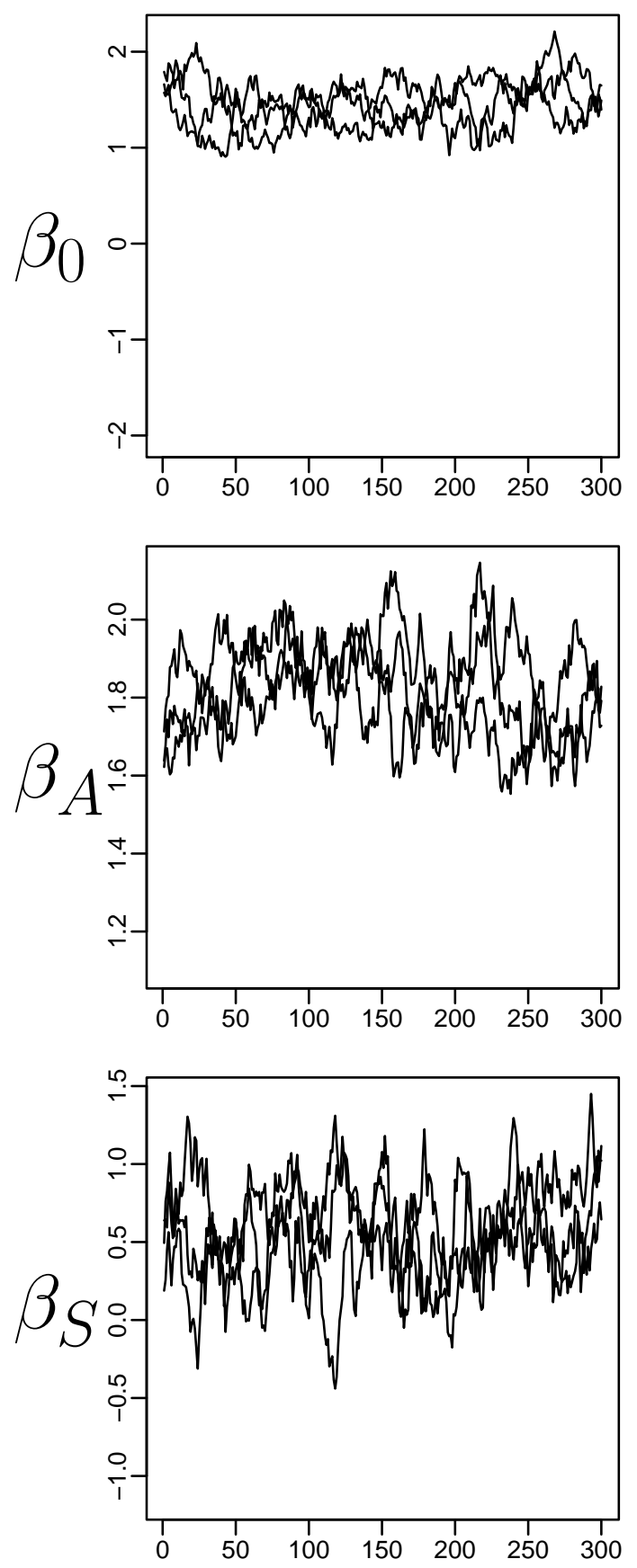

L. pensylvanica
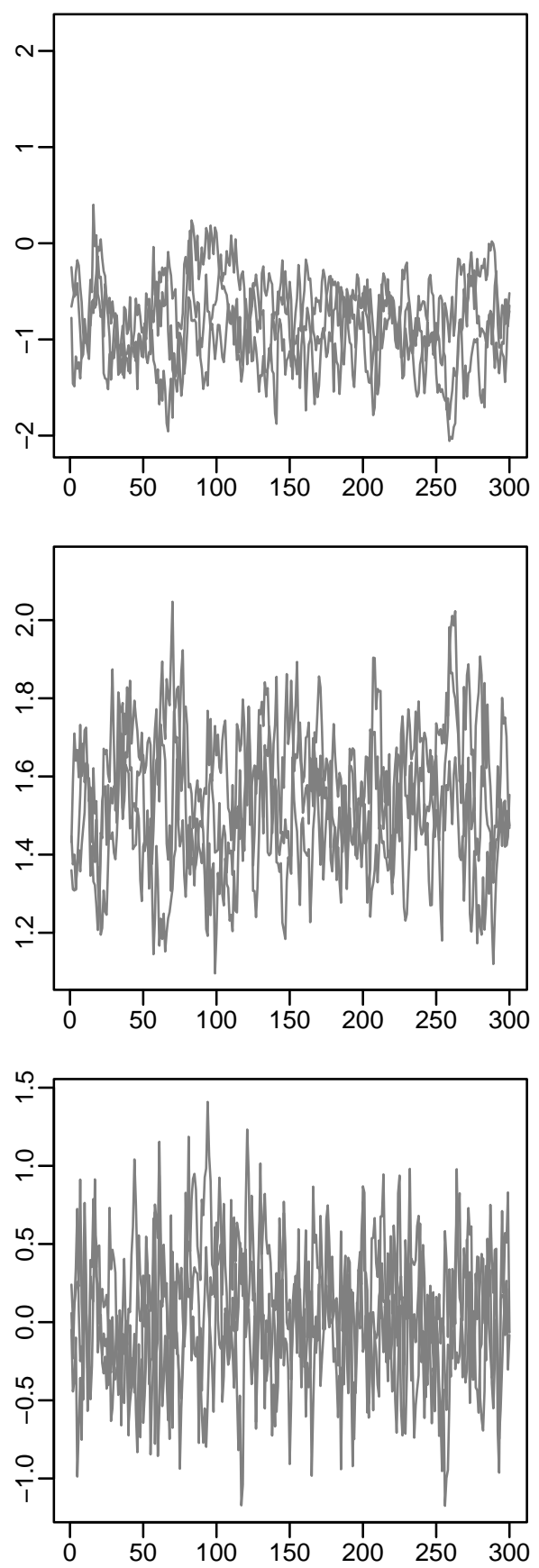

Sampling step (posterior density)
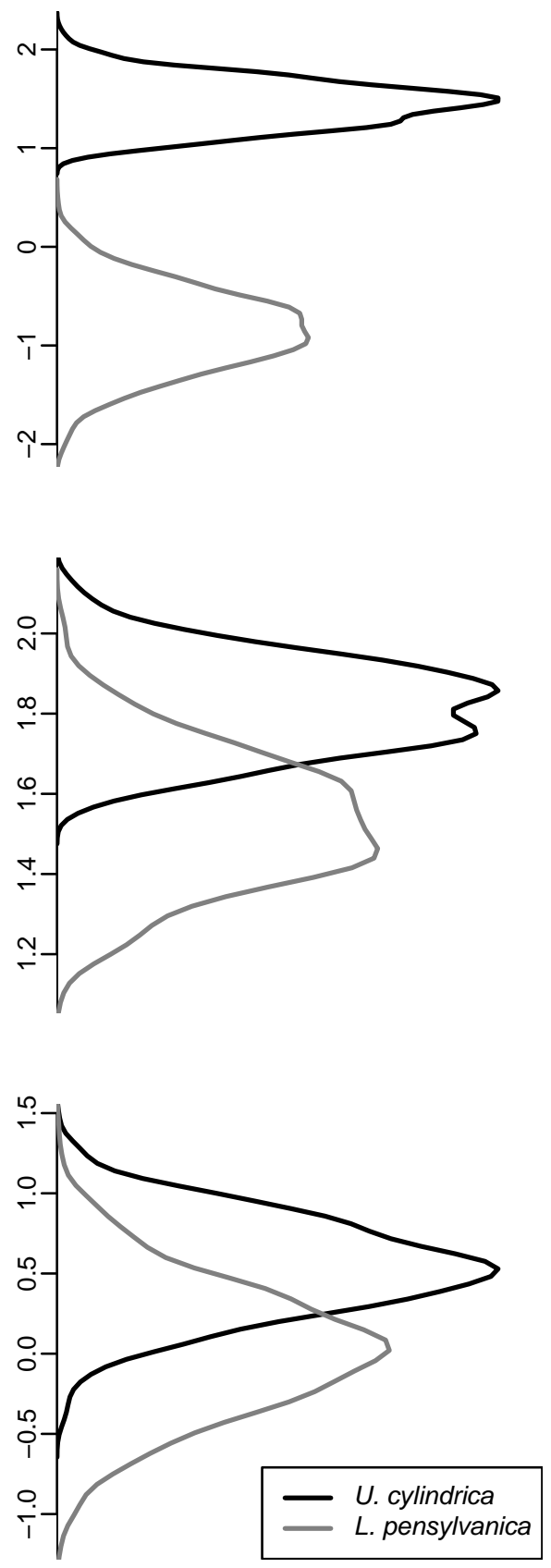